EMBRYARIDDLE
Aeronautical University

SCHOLARLY COMMONS
International Journal of Aviation, Aeronautics, and Aerospace

\title{
Performance Characteristics Design of Pulsed Plasma Thrusters for Drag Counter-Reacting
}

\author{
Dr. Sam Dakka \\ The University of Nottingham, sam.dakka@tutanota.com
}

Follow this and additional works at: https://commons.erau.edu/ijaaa

Part of the Aerodynamics and Fluid Mechanics Commons, and the Propulsion and Power Commons

\section{Scholarly Commons Citation \\ Dakka, D. (2020). Performance Characteristics Design of Pulsed Plasma Thrusters for Drag Counter- Reacting. International Journal of Aviation, Aeronautics, and Aerospace, 7(4). https://doi.org/10.15394/ ijaaa. 2020.1530 \\ This Article is brought to you for free and open access by the Journals at Scholarly Commons. It has been accepted for inclusion in International Journal of Aviation, Aeronautics, and Aerospace by an authorized administrator of Scholarly Commons. For more information, please contact commons@erau.edu.}


Recent years have demonstrated an explosive interest in CubSats developments in both commercial and educational organizations. This is attributed to an increasing trend in space technology miniaturization that provided off the shelf components for the design architecture of CubeSats and enabled low cost access to space by piggy-backing on main payload launch space platforms. The typical price tag of launching a $1 \mathrm{U}$ to $3 \mathrm{U}$ CubeSats range between $\$ 50 \mathrm{~K}$ to $\$ 200 \mathrm{~K}$ depending on deployment altitude, however some companies planning to offer launch services for $\$ 10 \mathrm{~K}$ to $\$ 85 \mathrm{~K}$ in 2020 per CubSat (Nervold et al., 2016). Given the nature of launch payload being secondary, this implied limitation on the propulsion capabilities of the CubeSats in order not to pose a threat to the main mission payload and therefore constraint the breadth of their mission that they can carry out. Historically, due to the small size and volume of the CubeSats only hot and cold thrusters have been utilized that provided relatively high thrust but low specific impulse. Due to accelerating trends in space technology miniaturization electric propulsion system deployment was introduced but their performance characteristics are mainly limited by the spacecraft onboard electric power generation. Propulsion systems can be divided into two categories, electric propulsion and non-electric propulsion systems (Tummala \& Dutta, 2017) The first category such as ion thrusters, Hall effect thruster, plasma thrusters, and electrospray thrusters dependent on board electric power while the second category hot and cold gas thrusters and solid rocket systems do not require an active on-board power system, implying electric power required only for initial and termination of the propulsion process. These technology developments have accelerated the proposals for CubSats dedicated for lunar and interplanetary missions in addition to earth observation missions at very low earth orbits.

Electric propulsion systems can be designated into three classifications

- $\quad$ Electrostatic - Systems that accelerate the ionized atoms of the propellant via an electric field.

- $\quad$ Electromagnetic - Systems that use electric and magnetic fields in tandem to accelerate the propellant.

- $\quad$ Electrothermal - Systems that accelerate the propellant through thermal addition and expansion, leading to greater kinetic energy.

The focus of this study will be on pulsed plasma thrusters due to their current use for space exploration and their utilization flexibility. The paper will discuss the relevant analytical equations in order to determine the performance characteristics of pulsed plasma thrusters, based on semi-imperial relations and correlations. The performance equations for the thrust, the specific impulse, the specific power and thrust efficiency will be developed. Then the calculation of the power draw by the thruster are calculated for different altitudes between $200 \mathrm{~km}$ to $600 \mathrm{~km}$ under the assumption of non-deployable solar panel installed on one side of the CubeSat that is facing the sun. 


\section{PPT Equations}

The way pulsed plasma thrusters operate is by rapid release of energy $\mathrm{E}$ stored in a capacitor to provide momentum to small quantity of mass of plasma for high discharge velocity. This mass ejection from the propellant creates an impulse bit $\mathrm{I}$. Assuming the thruster is operating at a fixed frequency $f$, then a steady state thrust can be deemed equivalent represented by the following equation (Guman, 1976)

$$
T=f_{\mathrm{I}}
$$

And the corresponding steady state power delivered by the capacitor can be represented by the equation

$$
P=f E
$$

To charge the capacitor there might be power conditioning requirement with efficiency $n_{P}$ the bus required power $P_{b}$ can be represented by the following equation (Guman, 1976)

$$
P_{b}=\mathrm{f} E / n_{P}
$$

A relationship can be described between the discharge mass of the consumed propellant $\mathrm{m}$ and the equivalent steady state mass $\dot{m}$

$$
\dot{m}=\mathrm{fm}
$$

The specific impulse then

$$
I_{S P}=\frac{T}{\dot{m g}}=\frac{\mathrm{I}}{\mathrm{mg}}
$$

Where $\dot{m} \mathrm{~g}$ is the mass flow rate of the propellant, the thrust efficiency $n_{t}$ is equal

$$
n_{t}=\frac{T^{2}}{2 m P}=\frac{I^{2}}{2 m E}
$$

If power conditioning is included then the system efficiency $n_{s}$ is equal

$$
n_{s}=n_{p} n_{t}
$$

In pulsed plasma thruster, the thrust can be regulated by changing the pulse rate. And the electric power requirements are directly related to the pulse frequency.

The specific thrust $\mathrm{P} / \mathrm{T}$ is also independent of the pulse frequency (Guman, 1976). 


$$
\frac{P}{T}=\frac{E}{I}
$$

In general, the performance capability of the thruster can be described by plotting the thrust efficiency versus the specific impulse. For example, if the initial conditions of the pulses with respect to the discharges did not vary this can be represented by a single point at the performance plot, however if the initial conditions have changed, for example charging the capacitor voltage was not maintained, then a different point can be represented in the performance capability of the thruster (Guman, 1976). And therefore, it is relatively easy to have broader performance capability for PPT and the equations above describe those broader performance capabilities.

Past experiences have demonstrated that the specific thrust, is mainly function of the geometry of the Teflon propellant inside the electrode nozzle. It has been shown that changing the propellant geometry to $\mathrm{V}$ shaped as compared with breech fed with parallel faces to the nozzle exit had reduced the power requirement for a given thrust levels (Guman, 1976). Furthermore, thruster nozzle configuration, feeding the propellant from the sides has also an impact on the magnitude of the specific thrust. From thruster designer point of view selecting the propellant geometry that will induce the lowest power requirement is desirable, however sometimes due to other constraints such as system weight or total number of thruster discharges, the desirable approach is the selection of high power from the perspective of the thruster designer.

The number of capacitor discharge pulses is

$$
\mathrm{n}=I_{t} / I
$$

Where $I_{t}$ is the total impulse, for each impulse bit evaluated, it is possible to calculate the capacitor charge energy based on the following equation

$$
\mathrm{E}=\mathrm{I} /(\mathrm{I} / \mathrm{E})
$$

The impulse bit to energy ratio is a function of the propellant nozzle energy. The power $\mathrm{P}$ into the capacitor can be estimated by the equation

$$
\mathrm{P}=\mathrm{T} /(\mathrm{T} / \mathrm{P})=\mathrm{T} /(\mathrm{I} / \mathrm{E})
$$

\section{Mission Statement}

A CubeSat is set to be launched into Low Earth Orbit and will be at an altitude between $200 \mathrm{~km}$ to $600 \mathrm{~km}$. At these altitudes, the CubeSat will encounter drag and this would affect how long the CubeSat can stay in orbit. To counter this, the thrust provided by the propulsion system must be equal to or above the value of the drag. This will require a new set of calculations to 
determine the drag at these altitudes, the orbital velocity, the density of air at these altitudes and the power available to the thruster by the CubeSat.

The CubeSat derive its power though the use of solar panels. Currently, the solar panels used for CubeSats are quite advanced, and can track the Sun's position for optimal energy absorption. The power absorbed is determined by the area of the solar panel. The greater the area, the greater the power absorbed as there is more surface area exposed to the Sun, increasing the chance of photon collection. The equation for power collected is the following:

$$
E=A_{P} r R P
$$

Where $E$ is the energy collected in $k W, A_{P}$ is the surface area of the panel in $m^{2}, r$ is the solar panel efficiency, $R$ is the average solar radiation in $\mathrm{kW} / \mathrm{m}^{2}$ and $P$ is the performance ratio.

At LEO, the CubeSat will be going at a certain orbital velocity that is dependent on its distance from Earth. The equation for the orbital velocity is the following:

$$
v_{o}=\sqrt{\frac{G M_{E}}{R_{E}+H}}
$$

Where $v_{o}$ is the orbital velocity in $\mathrm{m} / \mathrm{s}, G$ is the gravitational constant in $\mathrm{m}^{3} \mathrm{~kg}^{-1} \mathrm{~s}^{-2}, M_{E}$ is the mass of the Earth in $\mathrm{kg}, R_{E}$ is the radius of the Earth in meters and $H$ is the elevation above Earth in meters. equation:

The drag the CubeSat encounters is determined by the following

$$
D=\frac{\rho v_{o}^{2} A_{R} C_{D}}{2}
$$

Where $D$ is the drag in $N, \rho$ is the density of air in $\mathrm{kg} / \mathrm{m}^{3}, v_{o}$ is the orbital velocity in $\mathrm{m} / \mathrm{s}, A_{R}$ is the reference area in $\mathrm{m}^{2}$ and $C_{D}$ is the drag coefficient.

For the spacecraft to remain in orbit, the thrust must be greater than or equal to the atmospheric drag at a certain altitude. The power required by the thruster to counteract the atmospheric drag is calculated using a modification of thrust that is replaced by the atmospheric drag

$$
P_{R}=\frac{D I_{S p} g}{2 \eta_{T}}
$$




\section{Results and Analysis}

\section{CubeSat Parameters}

From (12), the energy collected by the CubeSat can be calculated. The average solar radiation in the upper regions of the atmosphere is approximately $1.368 \mathrm{~kW} / \mathrm{m}^{2}$ (Ag.tennessee.edu, 2020) The region from which the CubeSat will be in orbit is within a range of 200-600 km. The efficiency of the solar cells in use will be considered at a $29.5 \%$, taken from the EnduroSat website, a designer of CubeSat solar panels (EnduroSat. 2019). The performance ratio will be considered at 0.75 as the performance ratio is within a range of $0.5-0.9$ (Photovoltaic-software.com, 2020). CubeSats sizes can vary with the smallest being $1 \mathrm{U}$, where the dimensions are $10 \mathrm{~cm} \times 10 \mathrm{~cm} \times 10 \mathrm{~cm}$. Combining multiple $1 \mathrm{U}$ systems create the larger systems i.e. 3U,6U,27U etc. Large CubeSat systems would require larger solar panels; therefore, the solar panel area will increase. Table A.1 provides a list of calculated values for the energy collected by the solar panels.

From (13), the value of the gravitational constant is $6.67408 \times 10^{-11} \mathrm{~m}^{3}$ $\mathrm{kg}^{-1} \mathrm{~s}^{-2}$, the mass of the Earth is $5.9722 \times 10^{24} \mathrm{~kg}$, the radius of the Earth is $6.3781 \times 10^{6} \mathrm{~kg}$ and the altitude range is 200 to $600 \mathrm{~km}$. It can be seen from Figure 1 that when the altitude is increased, the orbital velocity decreases steadily.

\section{Figure 1}

Orbital Velocity as a Function of Altitude

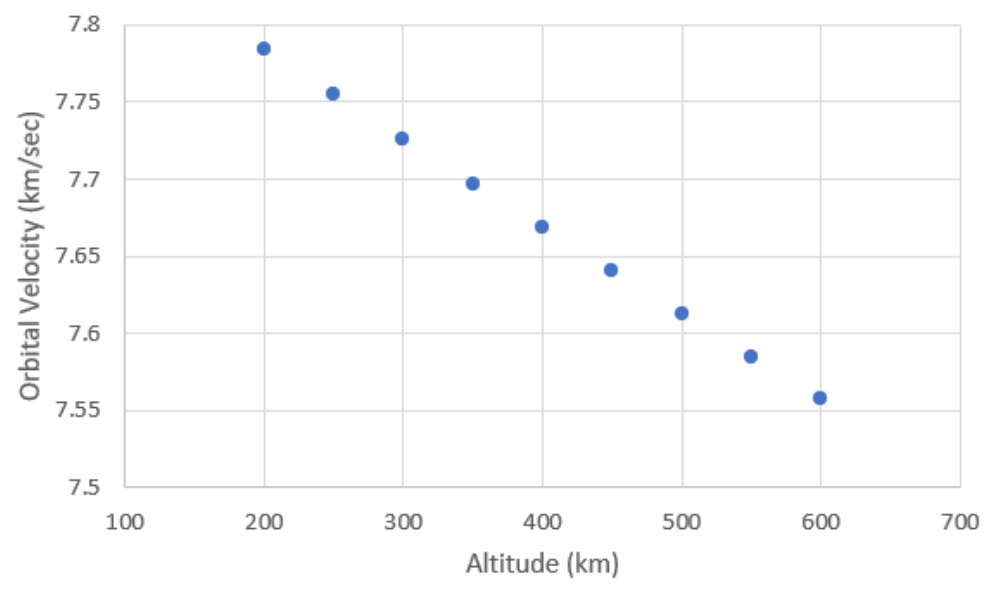


To calculate the drag, the values of the density within the $200-600 \mathrm{~km}$ range need to be found. At these altitudes, solar winds and the Earth's magnetic field cause changes to the densities in this region (Scied.ucar.edu., 2008) Solar activity is quite unpredictable so there are high, mean and low values for the densities. These approximate values of the density are taken from and listed in table A.2 (Ketsdever, 2008). The value of the drag coefficient of the CubeSats in the analysis was taken to be 2.1 (Scied.ucar.edu. 2008).

The Drag is calculated using the following equation (14) and the values are illustrated in Figure 2. The $1 \mathrm{U}$ and $2 \mathrm{U}$ drag magnitudes are on top of $3 \mathrm{U}$ and $12 \mathrm{U}$ is on top of $18 \mathrm{U}$.

\section{Figure 2}

Calculated Drag in $\mu N$ as a Function of Altitude for Various CubeSat Configurations

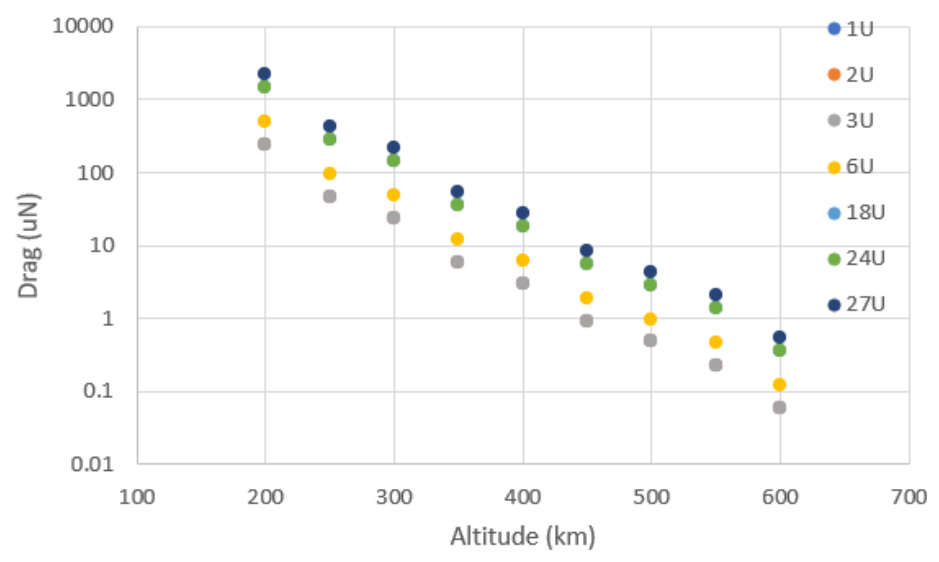

The thrust must be greater or equal to the atmospheric drag to maintain orbit. Another requirement is for the CubeSat to provide enough power to counteract the atmospheric drag. This is calculated using (15).

\section{Pulsed Plasma Thruster Analysis}

Historical data was gathered for PPT ((Antropov, et al, 2000; Burton \& Turchi, 1998; Cassady et al., n.d.; Ciaralli, 2014; Shaw,2011) and the data was divided into two groups. Group one data included performance characteristics for thrusters with breech fed propellant system and group 2 for thrusters with side fed propellants system. Figures 3 and 4 show historical data for PPT for breech fed system and side fed system respectively. Based on the historical data illustrated in the figures, two correlation were developed, the first correlation for the breech fed thruster indicate that the impulse bit to discharge energy ratio $\mathrm{I} / \mathrm{E}$ can be modelled as $\mathrm{I} / \mathrm{E}=16.244$. For the propellant side fed thruster the impulse bit to discharge energy ratio can be modelled as $\mathrm{I} / \mathrm{E}=23.216$. 


\section{Figure 3}

Impulse bit Versus Discharge Energy for Propellant Breech fed PPT (Teflon)

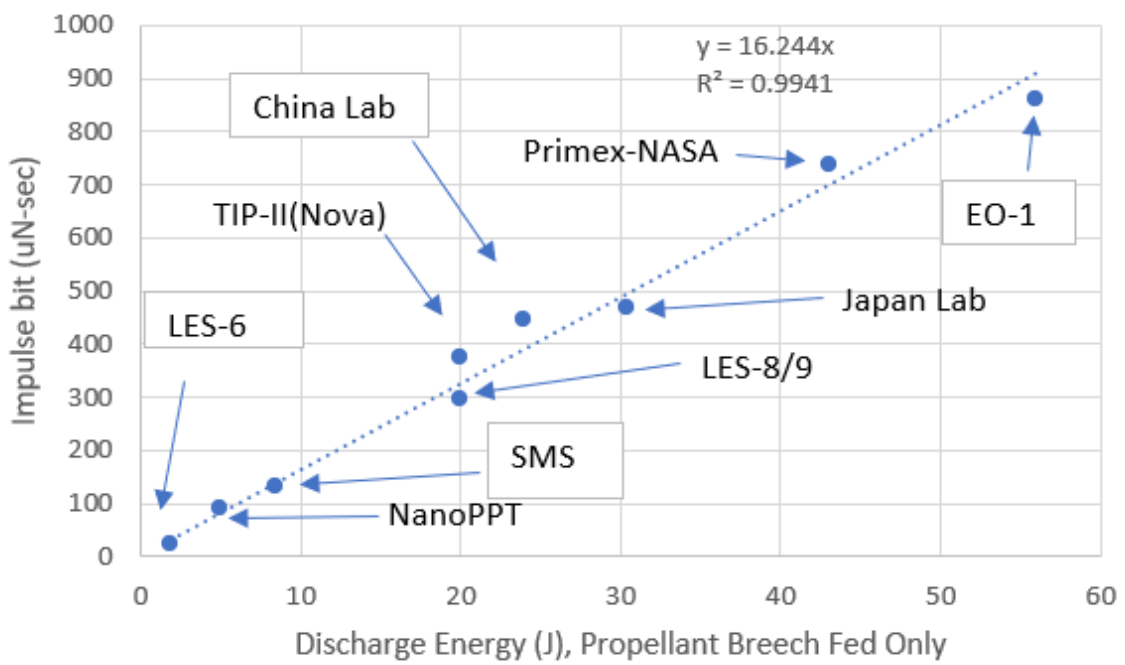

\section{Figure 4}

Impulse bit Versus Discharge Energy for Propellant Side fed PPT (Teflon)

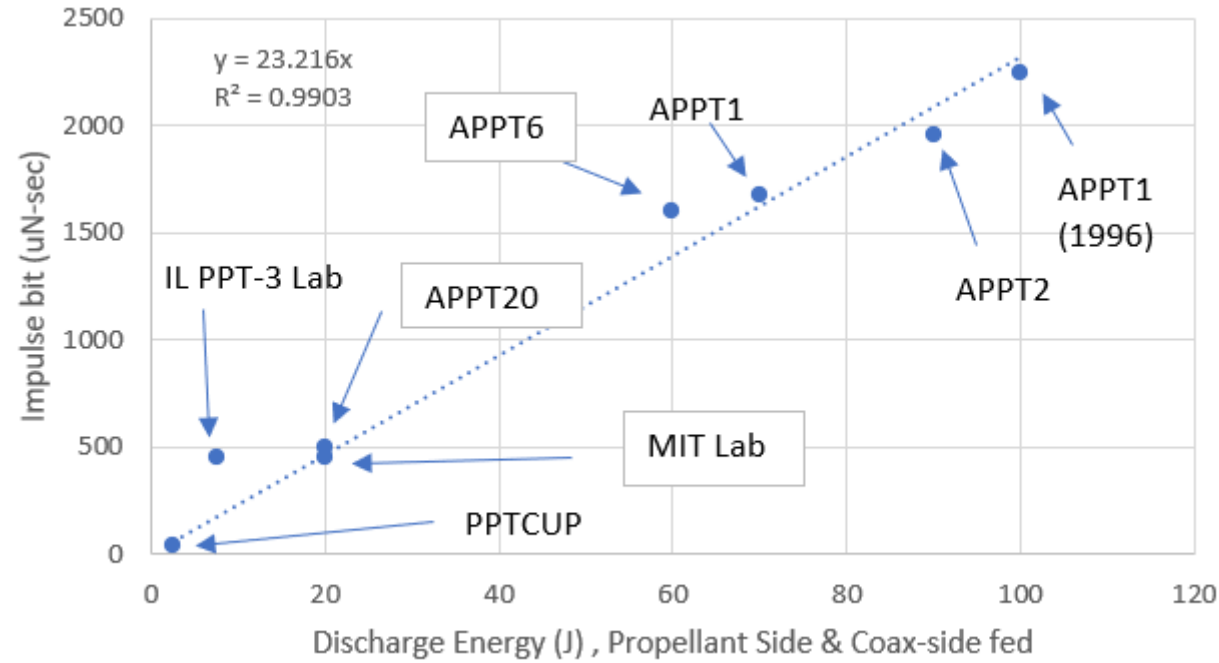

The drag values for different CubeSats Configuration was illustrated by figure 2. And the power required by the PPT for each CubeSat can be calculated based on equation (36) by utilizing the correlation developed by the plots 3 and 4 and replacing the thrust by the drag values of Figure 2 . 
Figures 5 and 6 illustrate the power required as a function of altitude for various CubeSat configurations for breech fed propellant system and side fed propellant system respectively for Teflon. By looking at the plots we conclude that the power requires for side fed system is lower than breech fed system.

\section{Figure 5}

Power Required Versus Altitude for Breech fed Propellant for Various CubeSat Configurations (Teflon)

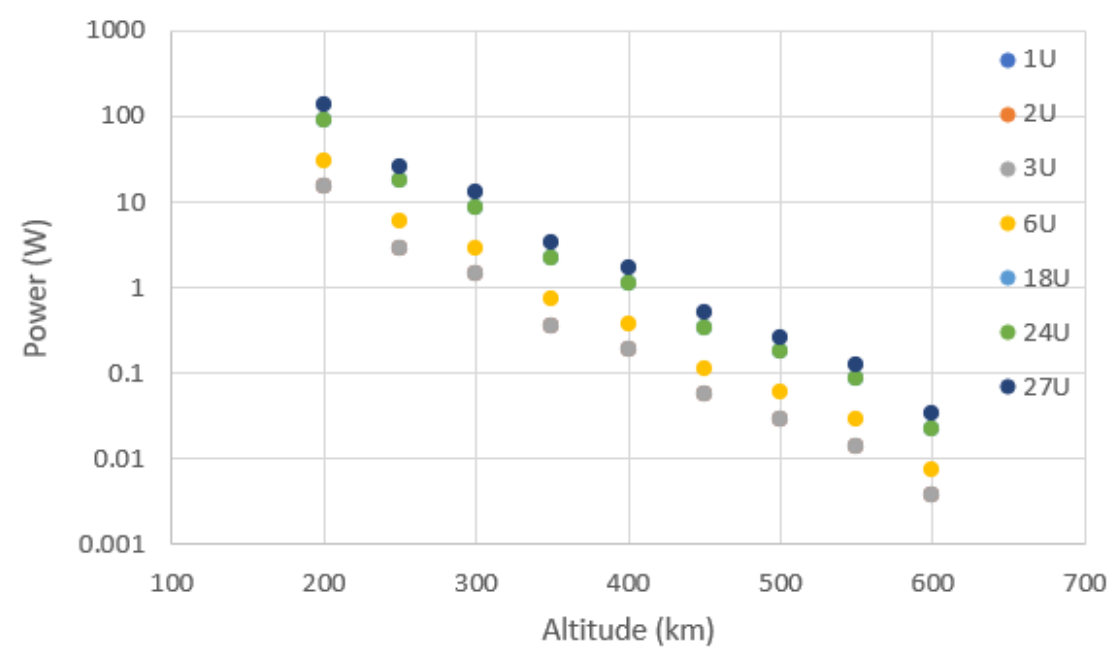




\section{Figure 6}

Power Required Versus Altitude for Side fed Propellant for Various CubeSat Configurations (Teflon)

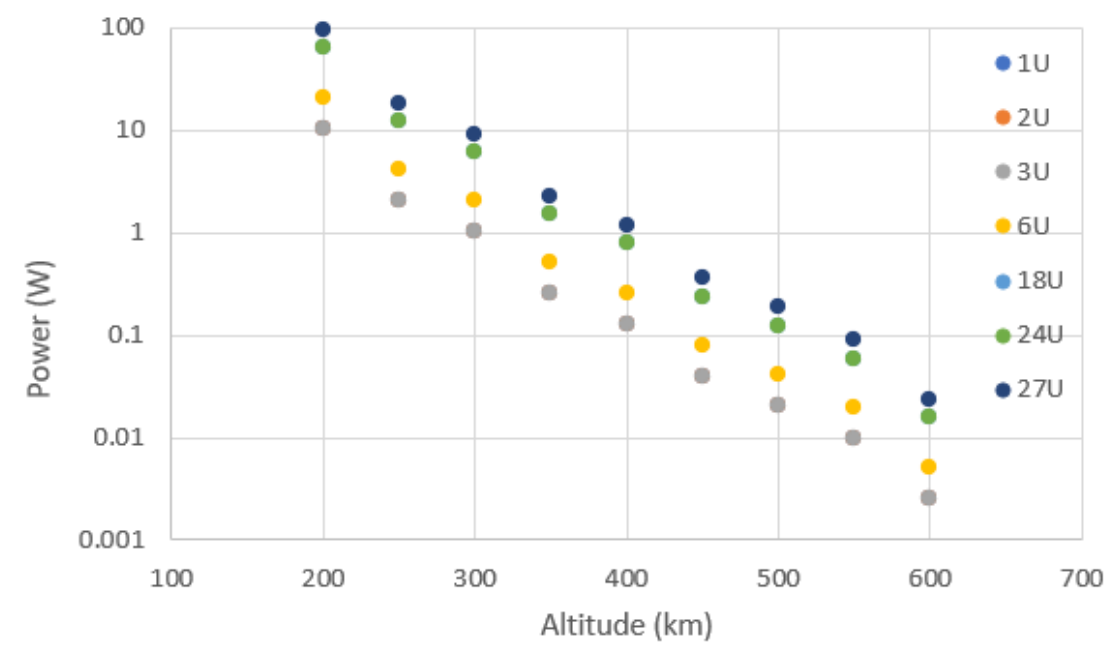

Figure 7 illustrates and highlight the power required differences between the breech fed and side fed PPT. In order to prevent the plot from being busy only the two boundary cases are highlighted at the high power and the low power values for $27 \mathrm{U}$ and $1 \mathrm{U}$, respectively. The dark brown circles represent the propellant side fed as compared dark graphite circles which represent the propellant breech fed for $27 \mathrm{U}$ CubeSat. The dark Navy circles compared to the light graphite circles which represent the required power for $1 \mathrm{U}$ CubeSat. The data clearly shows that the side fed PPT require less power than the breech fed system. 


\section{Figure 7}

Power Required Comparison Between Breech fed and Side fed System, Only two Configurations for Side fed has been Plotted for $1 U$ and $24 U$ Configurations (Teflon)

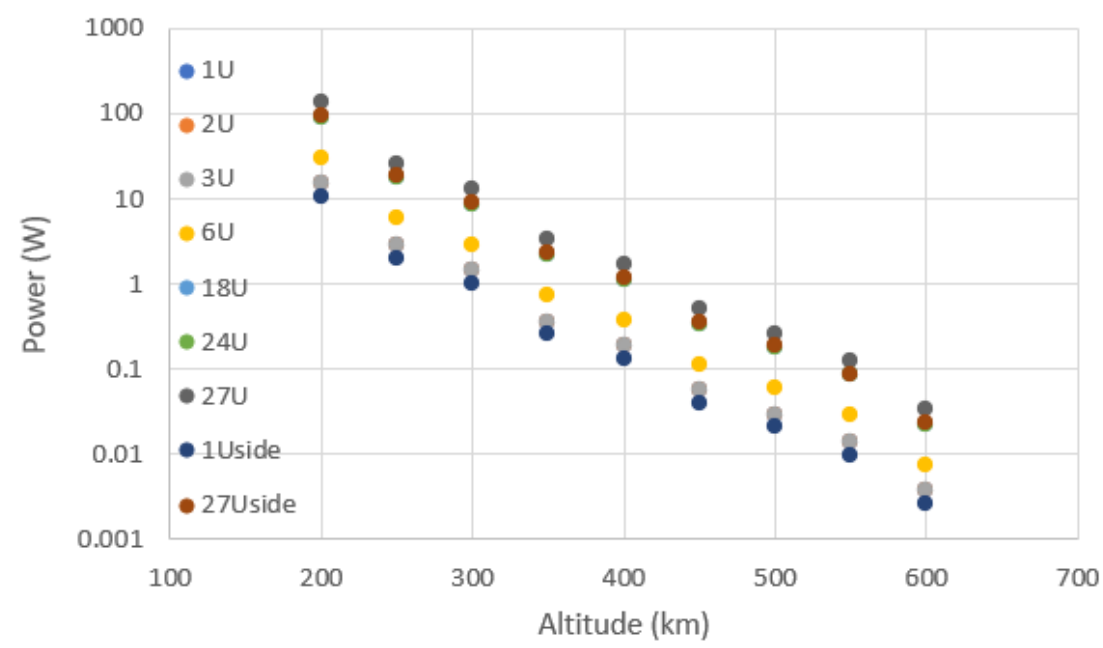

\section{Conclusions}

The study developed correlations for breech fed propellant design and side fed propellant design for PPT. The outcome showed thruster impulse bit to capacitor discharge energy ratio can be modelled $\mathrm{I} / \mathrm{E}=16.244$ and $\mathrm{I} / \mathrm{E}=23.216$ for breech fed and side fed respectively, for Teflon propellant. Based on this, the power required at various altitudes was calculated by substituting the thrust by the estimated drag values. The results also revealed that the magnitude of power required for side fed propellants designs are relatively lower than breech fed designs, the power required by breech fed propellant is lower by $30.03 \%$ compared with the side fed design, thus informing the spacecraft designer of the best route to pursue during the preliminary design campaign. 


\section{References}

Ag.tennessee.edu. (n.d.). The sun's energy. https://ag.tennessee.edu/solar/Pages/What\%20Is\%20Solar\%20Energy/ Sun's\%20Energy.aspx

Antropov, N. N., Popov, G.N., Yakovlev, V. N., Darnon, F., Kazeev, M., N., Akimov, V. N., Ogloblina, I.S., \& Nagel, Y.A. (2000). Application of pulsed plasma thrusters for small satellites. Proceedings of the international conference on spacecraft propulsion. Cannes, 10-13 October.

Burton, R. L., \& Turchi, P. J. (1998). Pulsed plasma thruster. Journal of Propulsion and Power, 14(5). https://doi.org/10.2514/2.5334

Cassady, R. J., Meckel N. J., Hoskins, W. A., Myers, R. M., Oleson, S. R., \& McGuire M. (n.d.). Pulsed plasma thruster systems for spacecraft attitude control.

https://digitalcommons.usu.edu/cgi/viewcontent.cgi?article=2430\&con text=smallsat

Ciaralli, S. (2014) A study of the lifetime of miniaturized ablative pulsed plasma thrusters. University of Southhampton. http://eprints.soton.ac.uk/id/eprint/379251

EnduroSat. (2019). CubeSat $3 U$ solar panel X/Y | CubeSat by EnduroSat. https://www.endurosat.com/products/cubesat-3u-solar-panel-X-y/

Guman, W. J. (1976). Solid propellant pulsed plasma propulsion system design. Journal of Propulsion and Power, 13(1). https://doi.org/10.2514/3.57064

Ketsdever, A. (2008). The space environment I: Characteristics of the vacuum, neutral, and MMOD environments. http://eas.uccs.edu/ aketsdev/MAE\%205595_files/The\%20Space\%20 Environment\%20I.pdf

Nervold, A. K., Berk, J., Straub, J., \& Whalen, D. A. (2016) Pathway to small satellite market growth. Advances in Aerospace Science and Technology, 1, 14.

Photovoltaic-software.com. (n.d.). How to calculate output energy of PV solar systems. https://photovoltaic-software.com/principle-ressources/howcalculate-solar-energy-power-pv-systems

Scied.ucar.edu. (2008). Thermosphere - overview | UCAR Center for Science Education. https://scied.ucar.edu/shortcontent/ thermosphere-overview

Shaw, P. V. (2011) Pulsed plasma thrusters for small satellites [Doctoral dissertation]. University of Surrey Guildford. http://epubs.surrey.ac.uk/745999/1/Thesis_P_Shaw.pdf

Tummala, A. \& Dutta, A. (2017) An overview of cube-satellite propulsion technologies and trends. Aerospace 4(4), 58. 


\section{Appendix}

\section{Table A.1}

Surface Areas and Calculated Energy Collected by the Solar Panels

\begin{tabular}{lll}
\hline CubeSat & $\boldsymbol{A}\left(\boldsymbol{m}^{2}\right), \boldsymbol{B}\left(\boldsymbol{m}^{2}\right), \boldsymbol{C}\left(\boldsymbol{m}^{2}\right)$ & \multicolumn{1}{c}{$\boldsymbol{E}(\boldsymbol{W})$} \\
\hline $1 U$ & $(0.01)$ & $(3.0267)$ \\
$2 U$ & $0.01,(0.02)$ & $3.0267,(6.0534)$ \\
$3 U$ & $0.01,(0.03)$ & $3.0267,(9.0801)$ \\
$6 U$ & $0.02,(0.06)$ & $6.0534,(18.160)$ \\
$12 U$ & $0.04,(0.06)$ & $12.1068,(18.16)$ \\
$18 U$ & $0.06,(0.09)$ & $18.1602,(27.24)$ \\
$24 U$ & $0.06,0.08,(0.12)$ & $18.1602,24.213,(36.3204)$ \\
$27 U$ & $(0.09)$ & $(27.2403)$
\end{tabular}

From Table A.1, the values in parentheses are the max area being used for the solar panels' energy calculations in the rest of the analysis.

\section{Table A.2}

Magnitude of the Density at Various Orbital Altitudes for low, Mean, and High Solar Activity

\begin{tabular}{cccc}
\hline H(km) & $\rho\left(\mathbf{1 0}^{-12} \mathbf{k} / \mathbf{m}^{\mathbf{3}}\right)$ & $\rho\left(\mathbf{1 0}^{-12} \mathbf{k g} / \mathbf{m}^{\mathbf{3}}\right)$ & $\rho\left(\mathbf{1 0}^{-12} \mathbf{k g} / \mathbf{m}^{\mathbf{3}}\right)$ \\
& Low & Mean & High \\
\hline 200 & 330 & 385 & 440 \\
250 & 60 & 75 & 85 \\
300 & 26 & 38 & 49 \\
350 & 8.3 & 9.5 & 10 \\
\hline
\end{tabular}




\begin{tabular}{llll}
\hline 400 & 3.4 & 4.9 & 6.5 \\
450 & 0.95 & 1.5 & 2.7 \\
500 & 0.62 & 0.79 & 0.91 \\
550 & 0.15 & 0.38 & 0.57 \\
600 & 0.079 & 0.10 & 0.14 \\
\hline
\end{tabular}

\section{$\underline{\text { Nomenclature }}$}

T-Steady State Thrust

I - Impulse bit

$I_{S P}$ - Specific Impulse

E-Discharge Energy

$P$ - Capacitor Input Power

$I_{t}-$ Total Impulse Bit

$f$-frequency

$P_{B}-$ Bus Power

$\eta_{T}-$ Thrust Efficiency

$m$ - Discharge mass

$\dot{m}$ - steady state Discharge mass

$\eta_{s}-$ System Efficiency

$n$ - Number of pulses

$\eta_{p}-$ Conditioning Power Efficiency 